ORIGINAL ARTICLE

\title{
If the condom fits, wear it: a qualitative study of young African-American men
}

\author{
R A Crosby, C A Graham, W L Yarber, S A Sanders
}

See end of article for authors' affiliations

.....................

Correspondence to: R A Crosby, PhD, Kentucky School of Public Health, Division of Human Behavior, 121 Washington Avenue, Room 111C, Lexington, KY 40506 0003,USA; crosby@ uky.edu

Accepted for publication 13 January 2004
Sex Transm Infect 2004;80:306-309. doi: 10.1136/sti.2003.008227

Objective: To extend the current knowledge base pertaining to condom failure among young AfricanAmerican men by assessing their experiences with male condom use.

Methods: Qualitative assessments were conducted with 19 African-American men (aged 18-29 years) who had just been diagnosed with an STI and reported using condoms in the previous 3 months.

Results: Five categories were identified from the data. These categories pertained to: (1) the "fit and feel" of condoms; (2) condom brand and size; (3) application problems; (4) availability of condoms and lubricants; and (5) commitment to condom use. Common themes included reasons why men believed condoms would break or slip off during sex. Comfort problems, including tightly fitting condoms and condoms drying out during intercourse, were mentioned frequently. Condom associated erection problems were often described. Many men also noted that condom use reduced the level of sexual satisfaction for their female partners. Men noted that finding the right kind of condom was not always easy and it became apparent during the interviews that men typically did not acquire lubrication to add to condoms. Despite their expressed problems with using condoms, men were, none the less, typically emphatic that condom use is an important part of their protective behaviour against STls.

Conclusion: Men were highly motivated to use condoms; however, they experienced a broad range of problems with condom use. With the exception of losing the sensation of skin to skin contact, the vast majority of these problems may be amenable to behavioural interventions.
$\mathrm{P}$ revious studies have investigated errors and problems that may occur when young men use condoms. ${ }^{1-6}$ These studies have focused on two critical events that lead to condom failure: breakage and slippage. Only two studies have sampled men from a high risk population (men were sampled from an STI clinic). ${ }^{2}$ One study enrolled men (1854 years) attending STI clinics in Sydney, Australia. The study found that breakage and slippage were particularly common for a small number of men. ${ }^{4}$ The other enrolled primarily African-American men (15-29 years) from a US STI clinic and found that $78 \%$ of those diagnosed with gonorrhoea reported at least one of five events during the previous month (started sex without condom, removed condom before sex was over, flipped the condom over, breakage, or slippage). Among men attending the clinic but not diagnosed with an STI, 74\% reported at least one of these events. $^{2}$

Two observations regarding these studies are noteworthy. Firstly, each brought attention to a neglected aspect of STI prevention (that is, the value of correcting user errors). However, the initial findings have not been subsequently investigated to gain a more in-depth understanding. Clearly, identifying common user errors and problems among men is an important task, but one that does not currently lend itself entirely to the use of closed response data collection instruments. Secondly, only one study ${ }^{2}$ sampled men from a priority population for STI prevention in the United States. Evidence clearly suggests that African-American men (especially younger men) are particularly likely to be infected by HIV. ${ }^{7-9}$ Of interest, a nationally representative US study found that African-American men were four to five times more likely to experience condom slippage and breakage than men of other races. ${ }^{6}$

The purpose of this study was to extend the current knowledge base pertaining to condom failure among young African-American men by qualitatively assessing experiences using the male condom. Because young African-American men are disproportionately infected by STIs, we selected this population for initial study. Further, we sampled men newly diagnosed with an STI; thus, the findings may be useful in the development of clinic based prevention efforts.

\section{METHODS}

Study sample

From June through August 2003, 19 men attending an STI clinic were enrolled. Men were recruited during days and times that were arbitrarily selected. Eligibility criteria were: (1) African-American, (2) 18-29 years of age, (3) diagnosis (confirmed or presumptive) of an STI during the clinic visit, (4) reported they were not knowingly HIV positive, and (5) used a condom with a female partner in the past 3 months. Before discharge from the clinic, medical staff determined eligibility based on the first three requirements. Twenty men were referred to a male interviewer who established eligibility based on the latter two requirements. One man stated that he had not used condoms in the past 3 months. All of the remaining 19 eligible men volunteered to participate and provided written informed consent. The institutional review board at Emory University approved the study protocol. A \$30 incentive was provided.

\section{Data collection}

Interviews occurred in a private room adjacent to the examination rooms. The interviewer (RC) informed men that he wanted to "find out what kind of problems guys experience when they use condoms." Men were asked to describe any of the problems they may have experienced. The interviewer used prompts (as sparingly as possible) to help men think about problems that may have occurred. Prompts were simple phrases such as, "any problems putting the condom on?" or "do condoms ever slip off during sex?" Prompts were designed to normalise user errors and 
problems thereby potentially encouraging men to accurately disclose user related issues. Also, when men provided answers that were unclear or complex, the interviewer asked for clarification and (in many instances) summarised the response for men to verify. Interviews lasted 15-35 minutes, were recorded on audiotape, and were professionally transcribed.

\section{Data analysis}

Data were sorted into categories by the first author (RC). The second author (CG) conducted an independent and concurrent review of the data. The identified categories were then verified by the remaining authors (WY and SS).

\section{RESULTS}

Five categories were identified: (1) "fit and feel"; (2) brand and size; (3) application problems; (4) availability issues; and (5) commitment to use. Themes (typically focusing on negative events) relating to these categories are presented below.

\section{Category 1: "fit and feel"}

One commonly reported problem was that condoms dry out. Men described this problem from their perspective and their sex partners' perspectives. Nearly all of the men describing dryness problems suggested that the issue was primarily a comfort problem for their partners as opposed to themselves (one exception to this was two men who noted that unlubricated condoms typically "pinch" their pubic hairs, causing extreme discomfort). One man astutely observed that a dry condom remains stationary on him while it is constantly moving in and out of the woman's vagina. Men were aware that women disliked the sensation of intercourse when condoms became dry. As one man said, "I'm the type of person where if you're not feeling it, I'm not feeling it." Another man said that his female partners may "grin and bear it" when condoms dry out but even if sex continues "climaxing can be difficult under those circumstances."

Men related several strategies used to rectify dryness. For example, several men said they would simply take the condom off (often at the woman's request) and continue sex. One man noted that he would "switch out" one condom for another (a fresh one) during any given session of sexual intercourse. He (like a few others) noted that condoms typically don't dry out until sex has lasted 20 minutes or more. He described recently "switching out" condoms three times during a single sexual encounter and then stated his current infection resulted from an occasion where he had taken off a dry condom and continued sex without another condom ("that's why I'm here today-I didn't have the sense to put another one on").

Men were keenly aware that levels of vaginal secretions vary widely among women and they generally stated that dry condoms are more of an issue when secretions "dry up." This awareness that sex could become better or worse as a function of two factors (vaginal secretion and the amount of condom lubrication) was common.

Some men added lubrication to their condoms. Several said they use their saliva (as one said, "I kiss it") and many mentioned their occasional use of KY jelly. One man was very committed to using baby oil: "It (baby oil) suits me better""It creates more slip and slide." He noted that the baby oil helps him keep his erection. Others noted they would use any kind of lotion they could find to lubricate condoms. As one man stated, "If it dries out I'll usually put lotion on whatever I can find."

Several suggested that stopping sex to add lubrication was a hassle and could ruin the mood. Yet, men also said that sex with a dry condom is not as pleasurable and many believed that the dryness was responsible for breakage.

\section{Category 2: condom brand and size}

A common theme was that finding the right condom promotes improved use. As one man stated, "Condoms rarely break or slip off once you find the kind that suits you ... everybody has that one (brand) that they like best ... if you're gonna use em' make sure you're comfortable." One man emphatically stated, "If the condom is not comfortable when you start, it will probably break before you climax."

Men reported that some brands/sizes of condoms cause discomfort and erection problems. These problems were typified by one man (diagnosed with syphilis) who described his problem with condoms by saying, "my penis can't breathe" and another man who said, "they be chokin' you." The first man, like many other men in the study, noted that most brands and sizes fit too tightly and this can ruin sex. Men also commonly suggested that tight fitting condoms break ("pop"). With few exceptions, men reporting discomfort said that condoms from the clinic are too tight. They noted that an expensive brand (Magnum) is very comfortable and does not pop.

Loss of erection from tight fitting condoms was common. One man said that $90 \%$ of the reason that he sometimes does not use condoms is to avoid erection problems. Several stated that erection problems, caused by condoms, could be so frustrating that they would (despite knowing better) take off the condom and continue sex. Men attributing erection problems to condom use often described pain (from the tight fit), pinching (of the pubic hairs by the rim), and their fears of breakage with tight fitting condoms (as one man said, "small condoms pop almost every time"). Again, men noted that selecting the right brand was the key to avoiding these problems.

Men commonly blamed tight fitting condoms for slippage. One man stated that condoms only slip off when they are too small. Another stated, "the ones that are too tight are the ones most likely to ride up (and slip off)." Most men reporting problems with tightness noted that the unrolled condom did not cover the length of the penis. One stated that he got genital warts because the condom did not cover part of his penis. Some indicated that condoms would slip off as a result of being only partially unrolled. A few also said that they don't always unroll the condom all the way because doing so pinches their pubic hairs. Of interest, one man stated that he was "trapped between sizes" and described how regular condoms are too tight, but the larger condoms slip off. Finally, several men noted at least one past experience when a condom had slipped off during intercourse and remained inside a partner's vagina. Men described this event vividly and talked about the condom getting "lost" inside the vagina, where it was not easy to retrieve. In fact, one man talked about he and his partner going to the emergency room to have a condom retrieved.

Interestingly, one man suggested that it was very important to "find the right condom for the right female." He went on to note that some of his partners liked Magnums and some liked Trojans. He noted he had to keep these preferences straight in order to please "his women."

\section{Category 3: application and use problems}

The most common application error that men described in conjunction with breakage was trapped air. As one man said, "I don't pay attention to that (air in the condom) - I didn't even know you was supposed to." Another described his "trick" for expelling air; he would work the air pocket down to the rim and lift the rim just enough to let the air out. Some stated that tight fitting condoms were especially likely to trap 
air and one specifically noted a lack of condoms breakage since learning to expel trapped air.

Most men stated they did not have problems putting condoms on. However, further discussion suggested that men had unknowingly been making application errors. One man stated: "I just slap em' on." Nearly all of the men noted they would often place the condom on the penis with the wrong side facing up (this prevents proper unrolling). Although a few knew that the condom should then be discarded (because of pre-ejaculate), most said they turned the condom over and unrolled it.

Some men described the types of lubricants they used on condoms and freely included Vaseline and other oil based substances as valid options-not making a distinction between these and water based lubricants. Men also noted (without apparent concern) that condom packages had been opened with teeth and sharp fingernails.

A majority described at least one example of having the condom break and frequently linked breakage with application errors. Several stated that breakage had been a common occurrence and others believed their current STI resulted from breakage. Men typically said that they had fewer condoms "pop" as they became more experienced using condoms. One was particularly poignant, noting that when you are younger you are thinking about having sex, not how to use the condom. He suggested that experience is typically the teacher: "You're not gonna go out and ask someone, 'hey man how do you put on a condom'-you just take it on yourself to (learn)." Another said, "they used to break all of the time because I was inexperienced ... I had to learn how to put one on-I learned by reading the package." Indeed, a majority noted learning on their own, through friends, or by reading packages. None the less, several had learned how to apply condoms in highschool health classes (many recalled this vividly).

Breakage was common. Many men noted they could "feel it" when the condom broke and said they would immediately stop sex. One man said that he felt it break and he stopped sex then had another condom on within 10 seconds (he believed this caused his current chlamydia infection). Another told about his efforts to stop sex after breakage, but his female partner only began thrusting harder. Conversely, other men stated they often continued having sex after breakage, despite knowing better: "I kept going, but I didn't ejaculate"; another said, "I can feel the difference when it breaks...if it's with a regular partner I'll usually keep going." Whether men stopped or continued was often described as a function of whether the female partner was known and trusted.

\section{Category 4: availability of condom and lubricants}

Although men often expressed clear preferences for certain brands, they also said these brands might not be easily accessible or affordable. The comments of one man were typical: "Dry condoms are bad (implying they break); I've bought them by mistake-you have to use them." This comment is informative in that the man (like others in the study) was implying that once you acquire a condom you should use it. This may be a financial issue (that is, not to waste a condom) or an availability issue. Several men noted that they would obtain condoms from a clinic (despite problems with fit) simply because they were free. Others suggested that cost is less important than availability and described past problems finding well lubricated (and properly fitting) condoms. One man summarised the availability issue nicely by saying, "I may get stuck buying those old dry rubber ones." A quote from one captures sentiments expressed by many, "Late at night you don't have time to look aroundyou use what you can get."
A few noted that lubricants are not easy to carry around and that while they preferred to use a water based lubricant with a condom, this was not always available.

\section{Category 5: commitment to condom use}

Despite problems with "fit," application, and availability, men commonly endorsed condom use as an essential practice in their lives. A comment from one was typical: "I'm not a fan of condoms, but I have to use them to keep from getting STDs." Another remarked: "I try to use them (condoms) because I hate coming here." One noted that he was already at a disadvantage (relative to life expectancy) because he is African-American and that using condoms was necessary to him as a means of avoiding STIs that could make his life even shorter: "Having HIV puts an expiration date on you."

While commitment was strong, men described a number of problems that interfered with intentions. Men noted that they could become too aroused to think clearly enough to use a condom. One man stated, "Grinding before sex is a problem because you forget and slip it in. It is possible to stop and put a condom on but unless she insists, it may not happen-this is why I got my STD." Another noted that being drunk or high was likely to make him "want sex with my lady so bad" and that if she didn't care about using a condom then why should he care. Another (noting erection problems from condoms) said, "I'm not really feeling the person." $\mathrm{He}$ repeatedly suggested that he had to "bear down" and mentally discipline himself to use condoms. His comment and experience of condom use is typical of men who suggested that condom use is usually their intent but not always their behaviour.

Despite temptations not to use condoms, many expressed intention to use condoms on every occasion of sexual intercourse, except with a "main" partner (this was seemingly linked to strong fears of getting an STI from an "other" partner). The comments of one man are especially worth noting: "Once I do not use a condom with a girl, then we work into not using them at all." He subsequently suggested that he (or his partners) would feel that there was nothing left to lose by not using condoms.

\section{DISCUSSION}

This qualitative study of men newly diagnosed with an STI, produced unique data that provide multiple insights about condom failure. To avoid breakage and slippage-for example, men may have a strong brand and size preference for condoms. Men believed that many negative events they described (including slippage and erection problems) were related to lack of adequate lubrication. Application errors were common. Indeed, men frequently suggested that negative events might be caused by these errors.

Men were generally dedicated to using condoms despite difficulties (for example, erection problems, discomfort, dryness, loss of pleasure). Men were keenly aware of their vulnerability to STIs and they did not mitigate the value of condom use. Yet, men had developed personalised standards for using condoms and some of these practices may be problematic for disease prevention.

A key strength of the qualitative design is the rich narrative. The relative importance for two of the factors (how well the condom fit and how well it felt during sex) was unanticipated given research findings from previous studies. ${ }^{1-6}$ Yet, these factors appear to be critically important with respect to events that precipitate condom failure. Indeed, the men seemed to be saying that condoms are important and should be used, but they expressed a desire to have condoms fit well and have adequate lubrication. The common theme that condoms are important is not surprising given the realities of high STI prevalence among young 


\section{Key messages}

- Men typically suggested that tight fitting condoms led to erection difficulties, slippage, and breakage. Although most men were aware that larger condoms could be purchased, they typically described problems with accessibility and cost. STI clinics might benefit men by providing a wide selection of various brands and sizes of condoms

- Problems caused by the inadequate lubrication of condoms were frequently mentioned by men in the study. The problems described (erection difficulties, slippage, and breakage) may easily precipitate user error (for example, taking the condom off) or condom failure that leads to the acquisition (or transmission) of an STI. Providing men with instruction and adequate supplies of lubrication may be beneficial

- Despite their description of various errors and problems associated with using condoms, men in this study were generally committed to using condoms. This commitment is positive and could form the basis for clinic based counselling protocols designed to help men refine their condom use skills

African-American men; however, we cannot rule out the possibility of a self presentation bias given these men were newly diagnosed with an STI (and were being interviewed directly afterwards).

Men's responses often suggested that achieving sexual pleasure was at odds with their desire to prevent acquisition of STIs. Although issues pertaining to loss of sensation could be reduced (for example, acquisition of correctly fitting and well lubricated condoms), the overall loss of skin to skin contact was clearly a concern. STI clinic practitioners could address these issues in the process of counselling their young African-American clients. However, further research is needed to determine how couples resolve these issues and whether one partner is more insistent on using condoms.

The findings also suggest that clinic based programmes could help men avoid problems with condom use. For example, breakage, slippage, and erection problems might be avoided by providing men with a wide selection of condoms and encouraging men to find a brand and size that fits and has adequate (and lasting) lubrication. Among low income clients, clinics may benefit men (thereby reducing STI transmission) by allowing them to return and replenish their supply of a favoured condom. STI clinics could also offer men supplies of lubrication (in pocket sized packages). One to one instruction may also be important as a strategy to help men apply condoms more efficiently. Providing this instruction immediately after men are diagnosed with an STI may be particularly effective as this opportunity represents a "teachable moment."

\section{Limitations and further research}

Findings based on this purposive sample should not be assumed to fairly represent the larger population of young African-American men newly diagnosed with an STD. Thus, while intriguing, the current findings should none the less be considered exploratory, especially given the possibility that men have exaggerated their commitment to condom use (that is, self presentation bias) and shifted the blame for condom failure to the product rather than user errors. Further research should build on the study findings to construct structured qualitative interviews that specifically collect event specific data (in a context that avoids self presentation bias).

\section{CONCLUSIONS}

Within the limitations of this qualitative study, findings suggest that men in this sample were highly motivated to use condoms, even before their current STI. Despite using condoms, men none the less acquired an STI, possibly due to user error. As opposed to product failure (an irresolvable problem), forms of user failure may be amenable to behavioural interventions. From a policy perspective, STI clinics may benefit men by providing a variety (that is, different brands and sizes) of free condoms and easy to carry packages of lubrication. From a patient education perspective, further research is needed to determine if men can benefit from a brief, interactive, education programme designed to rectify practices that may otherwise lead to user failure or the discontinuation of condom use.

\section{ACKNOWLEDGEMENT}

This study was funded by a grant from the National Institutes of Mental Health (1 R21 MH066682-01A1).

\section{Authors' affiliations}

R A Crosby, Kentucky School of Public Health, Division of Health Behavior, Lexington, KY, USA

R A Crosby, Emory Center for AIDS Research, Atlanta, GA, USA

R A Crosby, C A Graham, W L Yarber, S A Sanders, Rural Center for AIDS/STD Prevention at Indiana University, USA

W L Yarber, The Kinsey Institute for Research in Sex, Gender, and Reproduction, USA

C A Graham, W L Yarber, S A Sanders, Department of Applied Health Science at Indiana University, USA

C A Graham, W L Yarber, S A Sanders, Department of Gender Studies at Indiana University, USA

\section{REFERENCES}

1 Warner L, Clay-Warner J, Boles J, et al. Assessing condom use practices: Implications for evaluating method and user effectiveness. Sex Transm Dis 1998;25:273-7.

2 Mertz KJ, Finelli L, Levine WC, et al. Lovis ME. Gonorrhea in male adolescents and young adults in Newark, New Jersey: implications of risk factors and patient preferences for prevention strategies. Sex Transm Dis 2000;27:201-7.

3 Lindberg LD, Sonenstein FL, Ku L, et al. Young men's experience with condom breakage. Fam Plann Perspect 1997;29:128-31.

4 Richters J, Gerofi J, Donovan B. Why do condoms break or slip off in use? An exploratory study. Int J STD AIDS 1995;6:11-18.

5 Crosby RA, Sanders S, Yarber WL, et al. Condom use errors and problems among college men. Sex Transm Dis 2002;29:552-7.

6 Grady WR, Tanfer K. Condom breakage and slippage among men in the United States. Fam Plann Perspect 1994;26:107-12.

7 Rosenberg PS, Biggar RJ. Trends in HIV incidence among young adults in the United States. JAMA 1998;279:1894-9.

8 Rosenberg PS. Scope of the AIDS epidemic in the United States. Science 1995;270: 1372-5.

9 Centers for Disease Control and Prevention. HIV/AIDS among African Americans. Fact Sheet. Available at www.cdc.gov/hiv/pubs/facts/afam.htm, accessed 5 March 2001 